\title{
Muscular strength in male adolescents and premature death: cohort study of one million participants
}

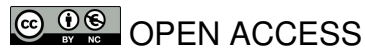

\author{
Francisco B Ortega research associate ${ }^{123}$, Karri Silventoinen research associate ${ }^{4}$, Per Tynelius \\ statistician $^{5}$, Finn Rasmussen professor ${ }^{5}$
}

1Department of Physical Education and Sport, School of Sport Sciences, University of Granada, Granada, Spain; ${ }^{2}$ Department of Biosciences and Nutrition at NOVUM, Karolinska Institutet, Huddinge, Stockholm, Sweden; ${ }^{3}$ Department of Medical Physiology, School of Medicine, University of Granada; ${ }^{4}$ Population Research Unit, Department of Social Research, University of Helsinki, Helsinki, Finland; ${ }^{5} \mathrm{Child}$ and Adolescent Public Health Epidemiology Group, Department of Public Health Sciences, Karolinska Institutet, Stockholm, Sweden

\begin{abstract}
Objectives To explore the extent to which muscular strength in adolescence is associated with all cause and cause specific premature mortality ( $<55$ years).

Design Prospective cohort study.

Setting Sweden.

Participants 1142599 Swedish male adolescents aged 16-19 years were followed over a period of 24 years.

Main outcome measures Baseline examinations included knee extension, handgrip, and elbow flexion strength tests, as well as measures of diastolic and systolic blood pressure and body mass index. Cox regression was used to estimate hazard ratios for mortality according to muscular strength categories (tenths).
\end{abstract}

Results During a median follow-up period of 24 years, 26145 participants died. Suicide was a more frequent cause of death in young adulthood (22.3\%) than was cardiovascular diseases $(7.8 \%)$ or cancer (14.9\%). High muscular strength in adolescence, as assessed by knee extension and handgrip tests, was associated with a $20-35 \%$ lower risk of premature mortality due to any cause or cardiovascular disease, independently of body mass index or blood pressure; no association was observed with mortality due to cancer. Stronger adolescents had a $20-30 \%$ lower risk of death from suicide and were $15-65 \%$ less likely to have any psychiatric diagnosis (such as schizophrenia and mood disorders). Adolescents in the lowest tenth of muscular strength showed by far the highest risk of mortality for different causes. All cause mortality rates (per 100000 person years) ranged between 122.3 and 86.9 for the weakest and strongest adolescents; corresponding figures were 9.5 and 5.6 for mortality due to cardiovascular diseases and 24.6 and 16.9 for mortality due to suicide.

Conclusions Low muscular strength in adolescents is an emerging risk factor for major causes of death in young adulthood, such as suicide and cardiovascular diseases. The effect size observed for all cause mortality was equivalent to that for well established risk factors such as elevated body mass index or blood pressure.

\section{Introduction}

Knowledge about different risk factors at early stages of life for later premature mortality is needed for disease prevention and early treatment. In addition to traditional risk factors, such as obesity and hypertension, a low cardiorespiratory fitness level during middle or older ages has been proposed as a powerful predictor of mortality. ${ }^{12}$ Another important health related component of fitness is muscular strength, which has been shown to be positively related to cardiorespiratory fitness. ${ }^{3}$ Although muscular strength has received far less attention than cardiorespiratory fitness, recent studies support the hypothesis that low muscular strength in adulthood also predicts all cause mortality, as well as mortality due to cardiovascular disease and cancer in healthy and diseased people. ${ }^{4-13}$ Whether muscular strength in childhood, adolescence, or both is a predictor of mortality is unknown. Mortality rates in young adulthood are very low in developed counties; consequently, large samples sizes and long follow-up periods are needed to accumulate enough cases to ensure appropriate statistical power in the analyses.

Suicide is the leading cause of death in young adults (25-44 years old) and a major public health concern in developed and developing countries. ${ }^{14}{ }^{15}$ Identification of early modifiable risk factors for suicide is therefore important for the design of successful strategies for suicide prevention.

In this study, we followed up more than one million male adolescents (16-19 years of age) recruited from the Swedish military conscription register to explore the extent to which 
muscular strength in adolescence is associated with all cause premature mortality (defined as death before 55 years of age), as well as cause specific premature mortality due to cardiovascular disease (coronary heart disease and stroke) and cancer. A second major aim was to study muscular strength in relation to mortality due to suicide. To obtain meaningful information about the clinical relevance of our results, we compared the effect sizes observed for associations between muscular strength and premature mortality with those for traditional disease risk factors such as body mass index and blood pressure. ${ }^{16-18}$ The associations of body mass index and blood pressure with mortality have previously been examined in depth in this population, ${ }^{17} 18$ and they are included in this study only for comparison purposes.

\section{Methods \\ Study sample and design}

We used data from the Swedish military conscription register for male adolescents born in Sweden between 1951 and 1976, according to the multi-generation register. ${ }^{19}{ }^{20}$ Conscription examinations are mandatory by law for all young male Swedish citizens, and they predate active military service; that is, they are also done for boys who do not later enter military service. ${ }^{21}$ During the years covered by this study, only boys with severe handicap or a chronic disease were exempted from the conscription. A total of 1194359 participants with valid data on age at conscription were available. Inclusion criteria were age 19 years or less ( $98.4 \%$ of the original sample) and availability of valid data on the main exposures (three strength tests, body mass index, and blood pressure), main confounders (year of birth, conscription age, conscription office), and main study outcomes (mortality). We defined premature death as death before the age of 55 years, following criteria used in previous studies on premature death. ${ }^{16}$ The entire study sample met these criteria. To minimise the risk of reverse causality, we excluded participants with less than one year of follow-up from the analyses $(n=985) .{ }^{132}$ Finally, we excluded those with extreme values for height (valid range $150-210 \mathrm{~cm}$ ), weight (valid range 40-150 kg), body mass index (valid range 15-60), or diastolic and systolic blood pressure (valid ranges 40-100 $\mathrm{mm} \mathrm{Hg}$ and 100-180 mm Hg) (n=1669). A total of 1142599 male adolescents (95.8\% of the sample) aged 16 to 19 years (mean age 18.3 (SD 0.5) years) met all the aforementioned criteria and were therefore included in main analyses (see appendix fig A). The Centers for Disease Control and Prevention defines the age range for adolescence as 10-19 years.

Accordingly, the baseline period studied here is considered late adolescence.

\section{Baseline examination}

During the conscription (baseline) examination, knee extension strength, handgrip strength, elbow flexion strength, diastolic and systolic blood pressure, and height and weight were measured, as previously described. ${ }^{1823}$ These muscular strength tests have been shown to have high reliability in young men ( $r=0.88-0.98) .{ }^{24}$ The Swedish Defence Recruitment Agency regarded the exact measurement protocol to be confidential information and did not reveal it to us. However, we observed in preliminary analyses that no systematic differences existed in the mean values of the measures between conscription offices, suggesting that a uniform protocol was used. The values of elbow flexion, handgrip, and knee extension strength in these data were similar to values in a previous study of young Finnish men, supporting the notion that standard protocols were used. ${ }^{24}$
We calculated body mass index as weight $(\mathrm{kg})$ divided by squared height $(\mathrm{m})$. Parental socioeconomic position in childhood came from population and housing censuses 1960-80 and parental level of education from the 1970 census. We retrieved participants' own highest achieved educational level from the educational register 1990-2004 (see sample sizes and study categories in appendix table A). ${ }^{25}$

\section{Follow-up and ascertainment of mortality}

We calculated the follow-up period as from the age of conscription until the earliest of three possible events: death, date of emigration, or end of follow-up (31 December 2006), whichever came first. The median follow-up period was 24.2 (range 1.0-37.3) years.

We used the cause of death register, ${ }^{26}$ and we categorised the underlying cause of death according to the eighth, ninth, and tenth revisions of the Swedish version of the international classification of diseases as coronary heart disease (410-414 for ICD-8 and ICD-9; I20-I25 for ICD-10), stroke (430-438, 344 for ICD-8, 430-438, 342, 344 for ICD-9; I60-I66, G45 for ICD-10), cancer (140-239 for ICD-8 and ICD-9; C00-D48 for ICD-10), suicide (E950-E959, E980-E989 for ICD-8 and ICD-9; X60-X64, Y10-Y34 for ICD-10), and non-intentional accidents (800-929 for ICD-8 and ICD-9; V01-X59 for ICD-10), as previously described. ${ }^{18} 25$ 27-29 Information about causes of death was available until 31 December 2004.

\section{Statistical analysis}

We used Cox proportional hazards regression to estimate hazard ratios and $95 \%$ confidence intervals for mortality according to exposure categories (tenths) of the three muscular strength tests separately. We did similar analyses for body mass index and blood pressure. We set the lowest tenth for muscular strength variables and the highest tenth for body mass index and blood pressure as reference groups, so that the hazard ratios would mostly range between 0 and 1 for all the exposures, allowing easier comparison among exposures. The main outcomes were all cause mortality and mortality due to cardiovascular disease, cancer, and suicide. We adjusted all the models for year of birth, conscription age, and conscription office. Additionally, we used adjusted models for simultaneous analysis of significant predictors - that is, muscular strength (knee extension, handgrip, or elbow flexion), body mass index, and blood pressure (diastolic or systolic). We used SPSS statistical software, version 19.0.0, for all statistical analyses.

\section{Results}

Appendix table A shows baseline characteristics of the whole study cohort, and appendix table B shows body mass index and blood pressure stratified by categories of muscular strength. Appendix fig B shows the distribution of muscular strength variables. Over the follow-up period (24.2 years), 26145 (2.3\%) participants died. Information on underlying causes of death was available for 22883 participants. Among these 22883 deaths, $1254(5.5 \%)$ were caused by coronary heart disease, 526 $(2.3 \%)$ by stroke, $3425(14.9 \%)$ by any type of cancer, 5100 (22.3\%) by suicide, and 5921 (25.9\%) by non-intentional accidents. We categorised the remaining deaths $(6657 ; 29.1 \%)$ as other causes of mortality. A combination of coronary heart disease and strokes (that is, cardiovascular disease) resulted in $1780(7.8 \%)$ deaths. Figures $1 \Downarrow, 2 \Downarrow, 3 \Downarrow$, and $4 \Downarrow$ show hazard ratios and $95 \%$ confidence intervals for all cause mortality and mortality due to cardiovascular disease, suicide, and cancer. 


\section{All cause mortality}

Higher levels of muscular strength were significantly associated with lower risk of all cause mortality. The association was stronger for knee extension and handgrip strength than for elbow flexion strength (fig $1 \Downarrow$ ). Compared with the weakest group (first tenth), higher levels (second, third, and fourth tenths) of muscular strength were monotonically associated with progressively reduced mortality risk. From the fourth tenth on, a plateau was achieved, with an approximate $20 \%$ risk reduction for premature mortality for knee extension and handgrip — that is, hazard ratios ranged from 0.78 to 0.84 and confidence intervals from 0.74 to 0.88 . We saw a similar effect size $(\sim 20 \%$ risk reduction) for body mass index and diastolic blood pressure, whereas the effect of systolic blood pressure was weaker than that of diastolic blood pressure (fig $1 \Downarrow$ ). Mutually adjusted analyses showed that muscular strength (knee extension or handgrip), body mass index, and diastolic blood pressure were independently associated with premature all cause death (fig $5 \Downarrow$ ). Analyses stratified by body mass index categories showed that muscular strength was inversely associated with all cause mortality within all body mass index categories - that is, underweight, normal weight, overweight, and obese adolescents

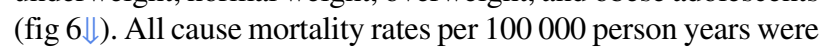
122.3 for adolescents with very low muscular strength, 98.9 for those with low to middle muscular strength, and 86.9 for those with and middle to very high muscular strength, as measured by the knee extension test (appendix table $\mathrm{C}$ ). The corresponding rates for handgrip muscular strength were 114.5, 96.5, and 90.9 (appendix table C).

\section{Cardiovascular disease mortality}

Body mass index and blood pressure (both diastolic and systolic) were strongly associated with premature mortality due to cardiovascular disease (fig $2 \Downarrow$ ). Muscular strength was not clearly associated with premature mortality due to cardiovascular disease in Cox models adjusted only for year of birth, age at conscription, and conscription office (fig $2 \Downarrow$ ), but it became significantly associated with cardiovascular disease mortality after additional adjustments for body mass index and diastolic blood pressure (see knee extension and handgrip strength in fig $5 \Downarrow$ ). The risk reduction was approximately $35 \%$ in high muscular strength groups, $60-70 \%$ in low body mass index groups, and $35-45 \%$ in low diastolic blood pressure groups, compared with the reference groups. We saw similar patterns when we did the analyses separately for coronary heart disease and stroke (data not shown). Mortality rates per 100000 person years due to cardiovascular disease were 9.5 for adolescents with very low muscular strength, 7.3 for those with low to middle muscular strength, and 5.6 for those with middle to very high muscular strength, as measured by the knee extension test (appendix table C). The corresponding rates for handgrip muscular strength were $8.3,7.3$, and 5.6 (appendix table C).

\section{Suicide mortality}

High muscular strength (knee extension and handgrip) was associated with a $20-30 \%$ lower risk of death from suicide (fig $3 \Downarrow$ ). We found a monotone and inverse association between body mass index and mortality due to suicide, whereas no clear association was apparent between systolic and diastolic blood pressure and suicide, as previously reported by our group..$^{30}$ The results persisted in the fully adjusted model (fig $5 \Downarrow$ ). Mortality rates per 100000 person years due to suicide were 24.6 for adolescents with very low muscular strength, 20.3 for those with low to middle muscular strength, and 16.9 for those with middle to very high muscular strength, as measured by the knee extension test (appendix table C). The corresponding rates for handgrip muscular strength were 22.4, 19.7, and 17.9 (appendix table C).

\section{Cancer mortality}

Body mass index was the only significant predictor of premature mortality due to cancer (fig $4 \Downarrow$ ), with a risk reduction of $25-35 \%$ in participants with low body mass index compared with those with high body mass index. The results persisted after mutual adjustment for the other exposures (appendix fig E).

\section{Additional analyses}

Appendix figures $\mathrm{C}$ and $\mathrm{D}$ show hazard ratios for mortality due to non-intentional accidents or other causes, to provide the full spectrum of cause specific mortality, but we do not discuss this further, as it is outside the scope of this study. In exploratory analyses, we observed that adolescents with a higher muscular strength level were $15-65 \%$ less likely to have any psychiatric diagnosis (that is, schizophrenia, other non-affective psychosis, mood disorders, neurotic and somatoform disorders, adjustment disorders, personality disorders, or alcohol related disorders, according to ICD-8/ICD-9 or ICD-10, as previously described ${ }^{31}$ ) at baseline (cross sectional association) and years later (longitudinal association) (see appendix fig F). We did this analysis after excluding participants with a psychiatric diagnosis before conscription. When we additionally adjusted the association between muscular strength and mortality due to suicide for psychiatric diagnoses either at baseline or years later, the association was attenuated and became non-significant (data not shown). Overall, little or no effect was apparent after further adjustment for socioeconomic factors (data not shown).

\section{Discussion}

Three major findings relevant for clinical practice and public health monitoring emerged from this prospective study. Firstly, muscular strength in adolescence, as assessed by handgrip and knee extension tests, is strongly associated with premature death from any cause, independently of body mass index or diastolic blood pressure. The effect sizes of these associations are similar to those of classic risk factors such as body mass index and blood pressure. Secondly, muscular strength is also associated with premature death from cardiovascular disease, independently of body mass index and blood pressure. Thirdly, stronger adolescents have a lower risk of mortality due to suicide, whereas no association is apparent with mortality due to cancer. After doing several systematic reviews and validation studies (as part of the ALPHA project: www.thealphaproject.net), we concluded that the handgrip test and tests of lower body muscle strength (jump tests, leg extension) are the most reliable, valid, and health related muscular strength tests. ${ }^{32}$ This could at least partially explain why the associations were stronger for handgrip and knee extension strength than for elbow flexion strength.

\section{All cause mortality and cardiovascular disease mortality}

Previous studies in adults or older adults have supported an association between muscular fitness and all cause mortality, cardiovascular disease mortality, or both. ${ }^{4-13}$ Our study provides new evidence for the importance of muscular strength in adolescence as predictor of premature mortality due to any cause or cardiovascular disease. In addition, our results suggest that the lowest tenth of population distribution of muscular strength 
in late adolescence has the greatest risk of all cause mortality in late life. Higher levels of strength are associated with additional risk reduction, and the risk reduction levels off close to the median (fourth to fifth tenths). This indicates that people with a muscular strength level equal to or higher than the population average have the same $20 \%$ risk reduction in all cause mortality, suggesting the need to target those with very low strength. Likewise, results from other cohort studies have reported similar reductions in the risk of mortality in men with middle versus high muscular strength, ${ }^{11}$ suggesting that having high levels of muscular strength does not provide additional "protection" against death compared with middle levels of muscular strength. The findings of this study also suggest that muscular strength in adolescence is as important as body mass index or blood pressure in terms of all cause mortality, whereas body mass index has a greater role than muscular strength or blood pressure in terms of mortality due to cardiovascular disease.

\section{Suicide mortality}

Unfortunately, we cannot discuss our results in relation to previous literature, as we have not found studies examining the association between muscular strength and suicide or between muscular strength and later psychiatric diagnosis. A few investigations, however, have focused on another component of physical fitness (that is, cardiorespiratory fitness) and suggest that high cardiorespiratory fitness in adulthood predicts a lower risk of depression, both in cross sectional and longitudinal studies. ${ }^{33}{ }^{34}$ Likewise, adolescents with a lower cardiorespiratory fitness level are more likely to have a diagnosis of psychosis or schizophrenia. ${ }^{35-37}$ Taken together, these findings support a link between cardiorespiratory fitness and mental health, which could in turn be related to suicidal behaviour.

In addition, we observed that adolescents with a higher muscular strength were less likely to have a psychiatric diagnosis at baseline and years later, which seemed to partly explain the lower risk of premature mortality due to suicide seen in this study. These findings suggest that physically weaker people might be more mentally vulnerable. Outlining a biological explanation for this association that could be reproduced in other studies is difficult. Reverse causation might partially explain this association. People with more mental problems (such as depression or schizophrenia) might be less likely to become involved in any social activity, including physical activities, which in turn would result in decreased physical fitness and lower muscular strength due to inactivity. On the other hand, depression and many other psychiatric disorders are highly related with a poor self concept and self esteem. ${ }^{38-41}$ Likewise, low physical fitness in general, and low muscular fitness in particular, has been found to be closely related to lower self concept/self esteem. ${ }^{42}$ Therefore, we could reasonably hypothesise that people with a very low muscular fitness have a worse self concept/self esteem, which may put them at higher risk of psychiatric disorders and suicide. This hypothesis is supported by several studies. ${ }^{434}$

\section{Cancer mortality}

The available literature is contradictory with respect to mortality due to cancer. Although some authors have observed an association between muscular strength and mortality due to cancer, ${ }^{611}$ others have found no association. ${ }^{510}$ Muscular strength was not associated with premature cancer mortality in our study. The large sample size in this study, and the resulting high statistical power of the analyses, strengthens the confidence in the null hypothesis (that is, no association between muscular strength and mortality due to cancer).

\section{Limitations}

This study is based on conscription data from 1969-94, and no information is available for female adolescents during this time period. Although some studies have observed significant effects in both men and women, ${ }^{7}$ most of available literature seems to supports the notion that low muscular strength might be a stronger predictor of mortality in men than in women..$^{4-6} 10$ This study is based on muscular strength of male adolescents and premature mortality among those who came to the conscription examination; we cannot know to what extent our findings apply to other populations. Unfortunately, cardiorespiratory fitness and physical activity data were not available, so we were unable to examine whether muscular strength is associated with premature mortality independently of these two factors. Nevertheless, several studies in adults and elderly people have reported that muscular strength is associated with mortality after adjustment for cardiorespiratory fitness or physical activity, ${ }^{711} 13$ suggesting that this might also be the case among adolescents.

\section{Strengths}

We followed more than one million male adolescents for 24 years. The large sample size and high statistical power allowed us to study cause specific mortality over the whole range of the distribution of muscular strength. To our best knowledge, this is the first study that links muscular strength assessed in an adolescent population with all cause and cause specific mortality many years later. Only a small study in female adolescents aged 17 years $(n=510)$ has linked cardiorespiratory fitness (the most studied fitness component) in early ages to all cause mortality. ${ }^{45}$ The inverse association between muscular strength and mortality due to suicide is a novel finding. Availability of information about psychiatric diagnoses from the conscription examination and also from psychiatric inpatient care during many years of follow-up allowed cross sectional and longitudinal analyses, which shed further light on the association between muscular strength and mortality due to suicide. Thanks to these data, we found that the association between muscular strength and mortality due to suicide seems to be partly mediated by psychiatric disorders.

\section{Clinical and public health implications}

Although several tests of muscular strength are available, the strongest evidence in relation to mortality has been reported for the handgrip strength test. ${ }^{4-10}{ }^{12}$ As handgrip strength can be assessed with good reliability in almost any place without additional costly equipment, it is a useful tool for clinical settings and for preventive services in schools and workplaces, for example. The study of premature mortality is of special relevance as a result of many years of life lost and also large productivity losses at the societal level. Although this study cannot disentangle causal pathways, physical training from childhood and adolescence seems to be needed. People at increased risk of long term mortality, because of lower muscular strength, should be encouraged to engage in exercise programmes and other forms of physical activity. In appendix tables D and E, we propose reference values and "healthy" muscular fitness zones based on the results of this study and reference values of European adolescents from the HELENA study. ${ }^{46}$ However, we acknowledge that these reference values are tentative and that further research in younger adolescents 
and female adolescents is needed before firm conclusions can be drawn.

\section{Conclusions}

This study provides strong evidence that a low level of muscular strength in late adolescence, as measured by knee extension and handgrip strength tests, is associated with all cause premature mortality to a similar extent as classic risk factors such as body mass index or blood pressure. Muscular strength is also associated with premature mortality due to cardiovascular disease but not that due to cancer. Finally, our data suggest that low muscular strength is associated with an increased risk of mortality due to suicide, supporting the notion that physically weaker people might also be mentally more vulnerable. Low muscular strength should be considered an emerging risk factor for major causes of death in young adulthood.

We are grateful to Jonatan R Ruiz, Manuel J Castillo, Michael Sjöström, and Steven Blair's group for constructive scientific discussions. We are also indebted to Charlotte Goodrose-Flores for the English revision.

Contributors: FR was responsible for the concept and design of the study. FR and PT acquired the data. PT created the dataset, and FBO did the statistical analysis and prepared the first draft of the manuscript. All authors were involved in further analysis and interpretation of data, drafting the manuscript, and critical revision of the manuscript for important intellectual content. They are all guarantors.

Funding: The study was supported by a grant to FR from the Swedish Research Council (grant 2007-5942). FBO was supported by grants from the Spanish Ministry of Science and Innovation (RYC-2011-09011). The funding bodies had no role in the preparation of this manuscript. Competing interests: All authors have completed the ICMJE uniform disclosure form at www.icmje.org/coi_disclosure.pdf (available on request from the corresponding author) and declare: the study was supported by a grant to FR from the Swedish Research Council, and FBO was supported by grants from the Spanish Ministry of Science and Innovation; no financial relationships with any organisations that might have an interest in the submitted work in the previous three years; no other relationships or activities that could appear to have influenced the submitted work.

Ethical approval: The study was approved by the Ethical Review Board, Stockholm, Sweden.

Data sharing: No additional data available.

1 Kodama S, Saito K, Tanaka S, Maki M, Yachi Y, Asumi M, et al. Cardiorespiratory fitness as a quantitative predictor of all-cause mortality and cardiovascular events in healthy men and women: a meta-analysis. JAMA 2009;301:2024-35.

2 Myers J, Prakash M, Froelicher V, Do D, Partington S, Atwood JE. Exercise capacity and mortality among men referred for exercise testing. N Engl J Med 2002;346:793-801.

3 Ortega FB, Ruiz JR, Castillo MJ, Moreno LA, González-Gross M, Warnberg J, et al. [Low level of physical fitness in Spanish adolescents: relevance for future cardiovascular health (AVENA study)] [Spanish]. Rev Esp Cardiol 2005;58:898-909.

4 Al Snih S, Markides KS, Ray L, Ostir GV, Goodwin JS. Handgrip strength and mortality in older Mexican Americans. J Am Geriatr Soc 2002;50:1250-6.

5 Fujita Y, Nakamura Y, Hiraoka J, Kobayashi K, Sakata K, Nagai M, et al. Physical-strength tests and mortality among visitors to health-promotion centers in Japan. J Clin Epidemiol 1995;48:1349-59.

6 Gale CR, Martyn CN, Cooper C, Sayer AA. Grip strength, body composition, and mortality. Int J Epidemiol 2007;36:228-35.

7 Katzmarzyk PT, Craig CL. Musculoskeletal fitness and risk of mortality. Med Sci Sports Exerc 2002;34:740-4.

8 Metter EJ, Talbot LA, Schrager M, Conwit R. Skeletal muscle strength as a predictor of all-cause mortality in healthy men. J. Gerontol A Biol Sci Med Sci 2002;57:B359-65.

9 Rantanen T, Masaki K, He Q, Ross GW, Willcox BJ, White L. Midlife muscle strength and human longevity up to age 100 years: a 44 -year prospective study among a decedent cohort. Age (Dordr) 2012;34:563-70.

10 Sasaki H, Kasagi F, Yamada M, Fujita S. Grip strength predicts cause-specific mortality in middle-aged and elderly persons. Am J Med 2007;120:337-42.

11 Ruiz JR, Sui X, Lobelo F, Morrow JR Jr, Jackson AW, Sjostrom M, et al. Association between muscular strength and mortality in men: prospective cohort study. BMJ 2008;337:a439.

12 Rantanen T, Harris T, Leveille SG, Visser M, Foley D, Masaki K, et al. Muscle strength and body mass index as long-term predictors of mortality in initially healthy men. J Gerontol A Biol Sci Med Sci 2000;55:M168-73.
13 Artero EG, Lee DC, Ruiz JR, Sui X, Ortega FB, Church TS, et al. A prospective study of muscular strength and all-cause mortality in men with hypertension. J Am Coll Cardiol 2011;57:1831-7.

14 Centers for Disease Control and Prevention (CDC). Leading causes of death, by age and sex-Utah, 1988-1992. MMWR Morb Mortal Wkly Rep 1994;43:685-7.

15 De Leo D, Evans R. International suicide rates and prevention strategies. Hogrefe and Huber, 2004.

16 Franks PW, Hanson RL, Knowler WC, Sievers ML, Bennett PH, Looker HC. Childhood obesity, other cardiovascular risk factors, and premature death. $N$ Engl J Med 2010;362:485-93.

17 Neovius M, Sundstrom J, Rasmussen F. Combined effects of overweight and smoking in late adolescence on subsequent mortality: nationwide cohort study. BMJ 2009;338:b496.

18 Sundstrom J, Neovius M, Tynelius P, Rasmussen F. Association of blood pressure in late adolescence with subsequent mortality: cohort study of Swedish male conscripts. BMJ 2011;342:d643.

19 Andreasson S, Allebeck P, Romelsjo A. Alcohol and mortality among young men: longitudinal study of Swedish conscripts. Br Med J (Clin Res Ed) 1988;296:1021-5.

20 Statistics Sweden. Multi-generation register 2010: a description of contents and quality. Department of Population and Welfare Statistics, Statistics Sweden, 2011.

21 Davey Smith G, Sterne JA, Fraser A, Tynelius P, Lawlor DA, Rasmussen F. The association between $\mathrm{BMI}$ and mortality using offspring $\mathrm{BMI}$ as an indicator of own BMI: large intergenerational mortality study. BMJ 2009;339:b5043.

22 Ortega FB, Lee DC, Sui X, Kubzansky LD, Ruiz JR, Baruth M, et al. Psychological well-being, cardiorespiratory fitness, and long-term survival. Am J Prev Med 2010;39:440-8.

23 Silventoinen K, Magnusson PK, Tynelius P, Kaprio J, Rasmussen F. Heritability of body size and muscle strength in young adulthood: a study of one million Swedish men. Genet Epidemiol 2008;32:341-9.

24 Viitasalo JT, Era P, Leskinen AL, Heikkinen E. Muscular strength profiles and anthropometry in random samples of men aged $31-35,51-55$ and $71-75$ years. Ergonomics 1985;28:1563-74.

25 Batty GD, Wennerstad KM, Smith GD, Gunnell D, Deary IJ, Tynelius P, et al. IQ in early adulthood and mortality by middle age: cohort study of 1 million Swedish men. Epidemiology 2009;20:100-9.

26 National Board of Health and Welfare. Causes of death-historical background, production methods and reliability. Sweden's Official Statistics, 2010.

27 Silventoinen K, Magnusson PK, Tynelius P, Batty GD, Rasmussen F. Association of body size and muscle strength with incidence of coronary heart disease and cerebrovascular diseases: a population-based cohort study of one million Swedish men. Int J Epidemiol 2009:38:110-8.

28 Batty GD, Whitley E, Deary IJ, Gale CR, Tynelius P, Rasmussen F. Psychosis alters association between IQ and future risk of attempted suicide: cohort study of 1,109,475 Swedish men. BMJ 2010;340:c2506.

29 Batty GD, Whitley E, Kivimaki M, Tynelius P, Rasmussen F. Body mass index and attempted suicide: cohort study of 1,133,019 Swedish men. Am J Epidemiol 2010;172:890-9.

30 Magnusson PK, Rasmussen F, Lawlor DA, Tynelius P, Gunnell D. Association of body mass index with suicide mortality: a prospective cohort study of more than one million men. Am J Epidemiol 2006;163:1-8.

31 Gale CR, Batty GD, Osborn DP, Tynelius P, Whitley E, Rasmussen F. Association of mental disorders in early adulthood and later psychiatric hospital admissions and mortality in a cohort study of more than 1 million men. Arch Gen Psychiatry 2012:69:823-31.

32 Ruiz JR, Castro-Pinero J, Espana-Romero V, Artero EG, Ortega FB, Cuenca MM, et al. Field-based fitness assessment in young people: the ALPHA health-related fitness test battery for children and adolescents. Br J Sports Med 2011;45:518-24.

33 Galper DI, Trivedi MH, Barlow CE, Dunn AL, Kampert JB. Inverse association between physical inactivity and mental health in men and women. Med Sci Sports Exerc 2006;38:173-8.

34 Sui X, Laditka JN, Church TS, Hardin JW, Chase N, Davis K, et al. Prospective study of cardiorespiratory fitness and depressive symptoms in women and men. $J$ Psychiatr Res 2009;43:546-52.

35 Koivukangas J, Tammelin T, Kaakinen M, Maki P, Moilanen I, Taanila A, et al. Physical activity and fitness in adolescents at risk for psychosis within the Northern Finland 1986 birth cohort. Schizophr Res 2010;116:152-8.

36 Wildgust $\mathrm{HJ}$, Beary M. Are there modifiable risk factors which will reduce the excess mortality in schizophrenia? J Psychopharmacol 2010;24(4 suppl):37-50.

37 Beary M, Wildgust HJ. Chronic disease to top agenda: cardiorespiratory fitness is an important risk factor. BMJ 2011;342:d1152.

38 Au AC, Lau S, Lee MT. Suicide ideation and depression: the moderation effects of family cohesion and social self-concept. Adolescence 2009:44:851-68.

39 Roberts JE, Shapiro AM, Gamble SA. Level and perceived stability of self-esteem prospectively predict depressive symptoms during psychoeducational group treatment. Br J Clin Psychol 1999;38:425-9.

40 Romm KL, Rossberg JI, Hansen CF, Haug E, Andreassen OA, Melle I. Self-esteem is associated with premorbid adjustment and positive psychotic symptoms in early psychosis. BMC Psychiatry 2011:11:136.

41 Garaigordobil M, Perez JI, Mozaz M. Self-concept, self-esteem and psychopathological symptoms. Psicothema 2008;20:114-23.

42 Greenleaf CA, Petrie TA, Martin SB. Psychosocial variables associated with body composition and cardiorespiratory fitness in middle school students. Res $Q$ Exerc Sport 2010;81(3 suppl):S65-74.

43 Babiss LA, Gangwisch JE. Sports participation as a protective factor against depression and suicidal ideation in adolescents as mediated by self-esteem and social support. $J$ Dev Behav Pediatr 2009;30:376-84.

44 Dishman RK, Hales DP, Pfeiffer KA, Felton GA, Saunders R, Ward DS, et al. Physica self-concept and self-esteem mediate cross-sectional relations of physical activity and sport participation with depression symptoms among adolescent girls. Health Psycho 2006;25:396-407.

45 Sato M, Kodama S, Sugawara A, Saito K, Sone H. Physical fitness during adolescence and adult mortality. Epidemiology 2009;20:463-4.

46 Ortega FB, Artero EG, Ruiz JR, Espana-Romero V, Jimenez-Pavon D, Vicente-Rodriguez $G$, et al. Physical fitness levels among European adolescents: the HELENA study. Br J Sports Med 2011;45:20-9.

Accepted: 19 October 2012 


\section{What is already known in this topic}

Muscular strength in adulthood is associated with all cause mortality and cardiovascular disease mortality

Whether low muscular strength in adolescence is associated with mortality is unknown; a long follow-up period and very large sample size would be needed to explore this

A higher cardiorespiratory fitness is associated with better mental health in adults, but whether muscular strength at any age is associated with future mental health and suicide mortality is unknown

\section{What this study adds}

Muscular strength in adolescence, as assessed by knee extension and handgrip tests, was associated with a $20-35 \%$ lower risk of all cause and cardiovascular disease premature mortality ( $<55$ years), independently of body mass index or blood pressure

Stronger adolescents had a $20-30 \%$ lower risk of death from suicide and were $15-65 \%$ less likely to have any psychiatric diagnosis (such as schizophrenia and mood disorders)

Adolescents in the lowest tenth of muscular strength showed by far the highest risk of mortality due to different causes

\section{Cite this as: BMJ 2012;345:e7279}

This is an open-access article distributed under the terms of the Creative Commons Attribution Non-commercial License, which permits use, distribution, and reproduction in any medium, provided the original work is properly cited, the use is non commercial and is otherwise in compliance with the license. See: http://creativecommons.org/licenses/bync/2.0/ and http://creativecommons.org/licenses/by-nc/2.0/legalcode. 


\section{Figures}
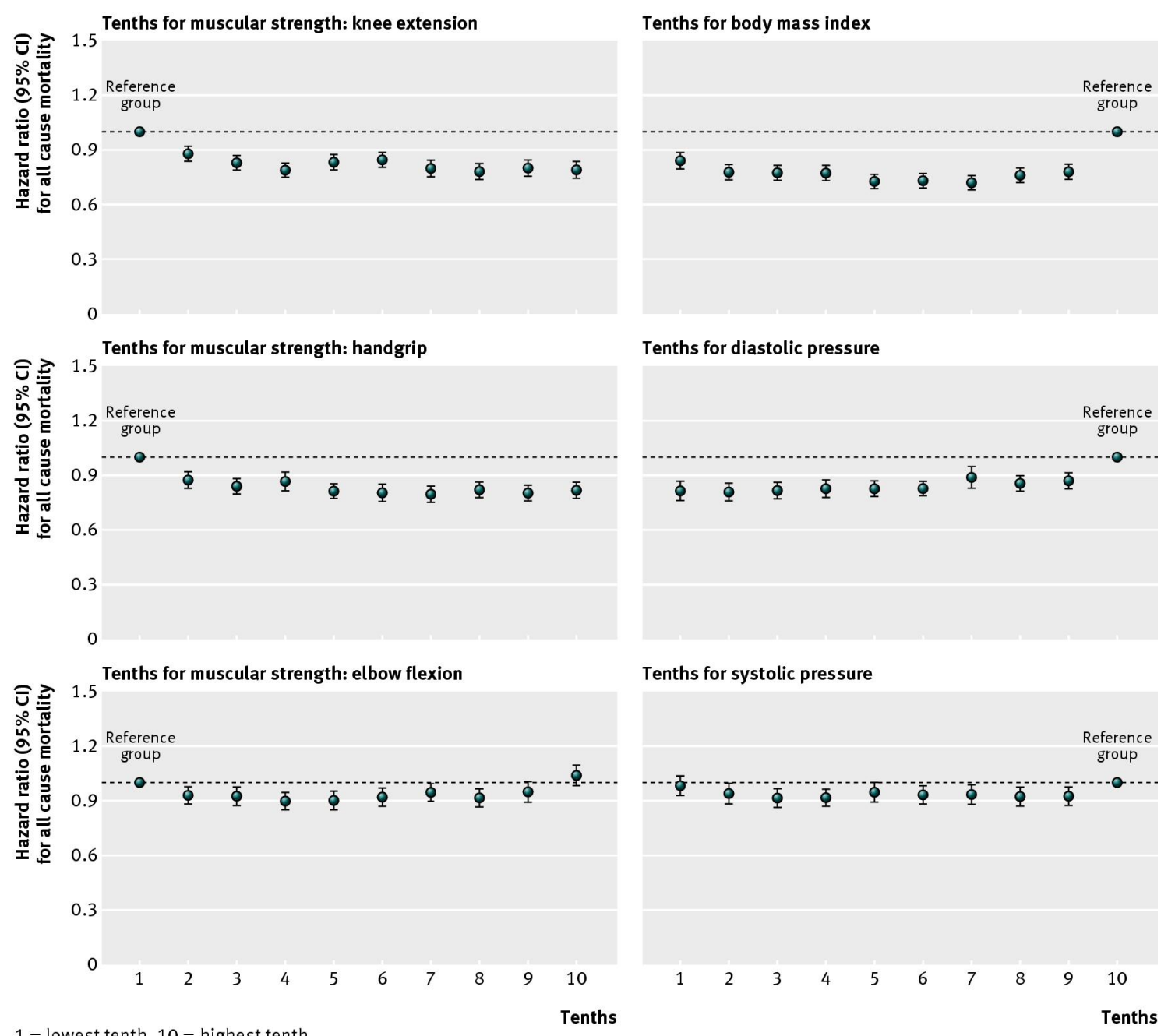

$1=$ lowest tenth, $10=$ highest tenth

Tenths

Fig 1 Hazard ratios $(95 \% \mathrm{Cl})$ for relation of muscular strength, body mass index, and blood pressure with all cause premature death. Models were adjusted for birth cohort, conscription age, and conscription office ( $n=1142599)$ 

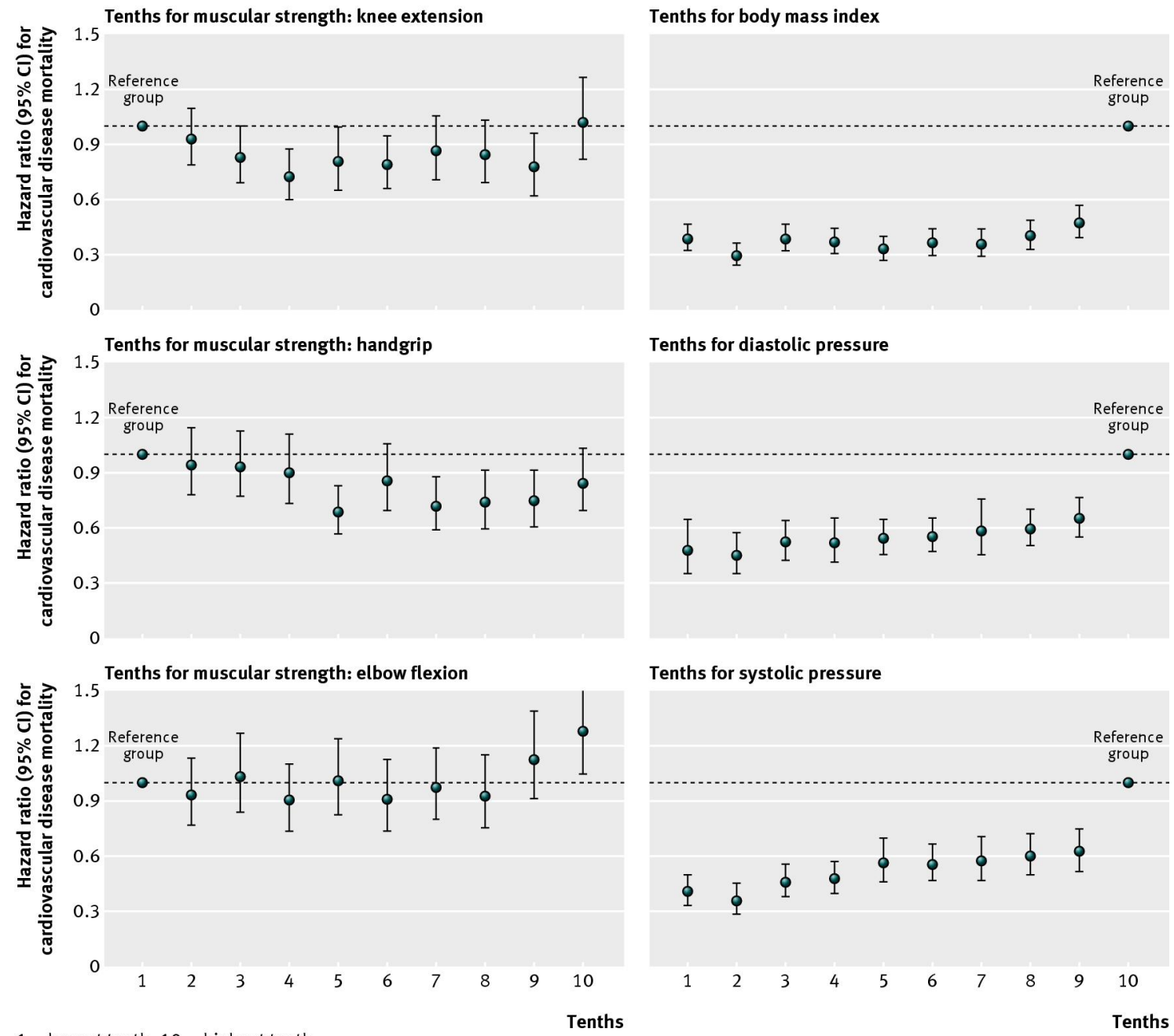

$1=$ lowest tenth, $10=$ highest tenth

Fig 2 Hazard ratios $(95 \% \mathrm{Cl})$ for relation of muscular strength, body mass index, and blood pressure with premature death from cardiovascular disease. Models were adjusted for birth cohort, conscription age, and conscription office ( $\mathrm{n}=1118154)$ 


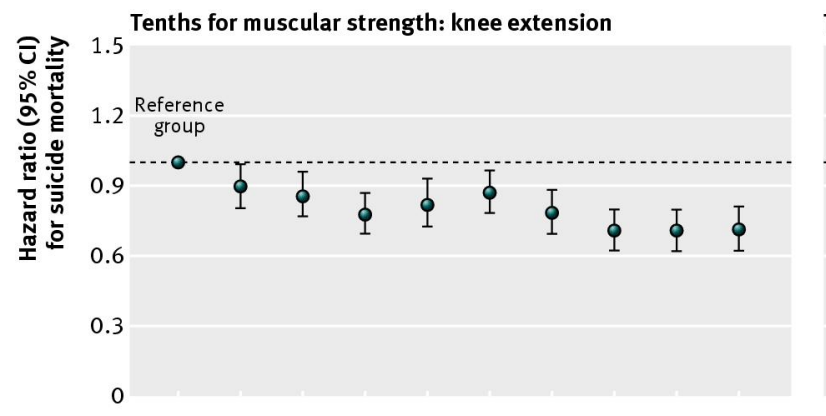

\section{Tenths for body mass index}

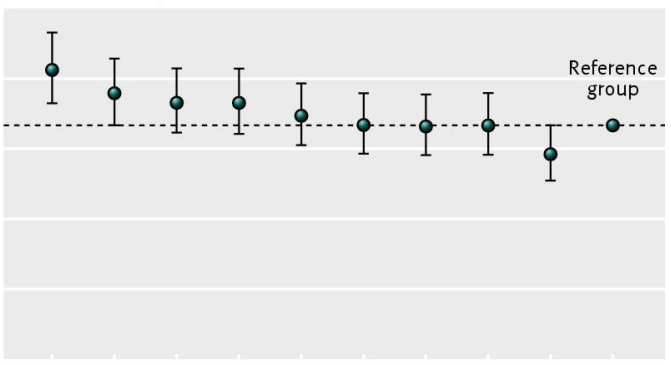

Tenths for diastolic pressure
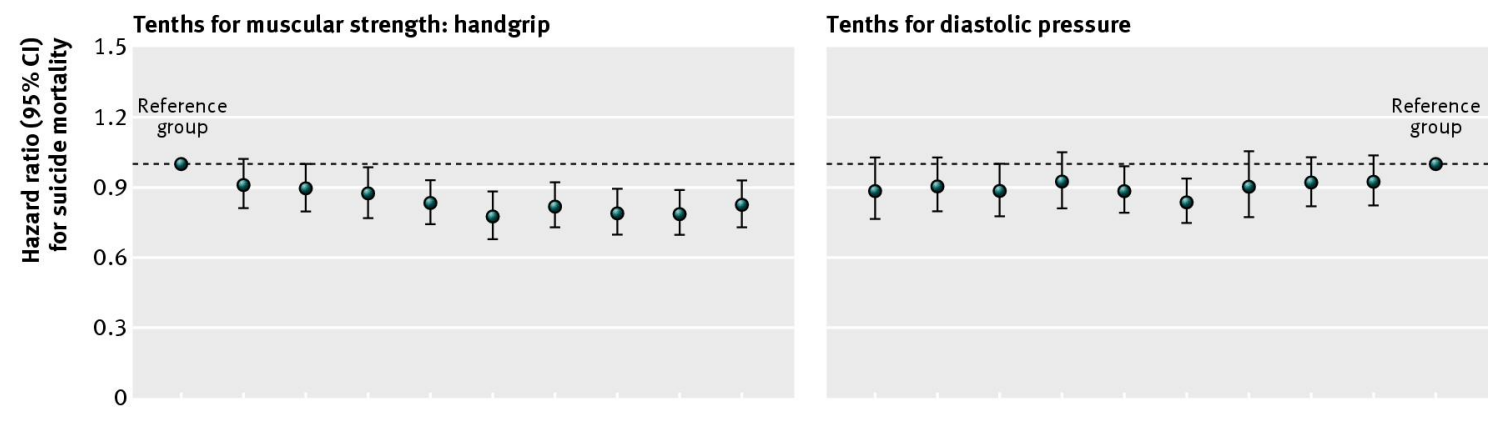

Tenths for systolic pressure

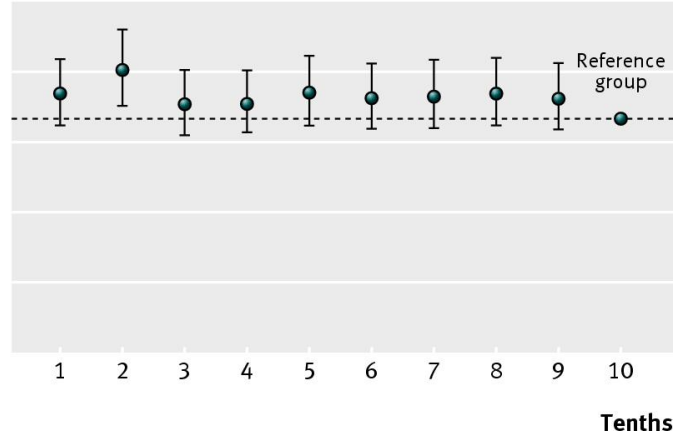

Tenths

$1=$ lowest tenth, $10=$ highest tenth

Fig 3 Hazard ratios $(95 \% \mathrm{Cl})$ for relation of muscular strength, body mass index, and blood pressure with premature death from suicide. Models were adjusted for birth cohort, conscription age, and conscription office $(n=1121480)$ 

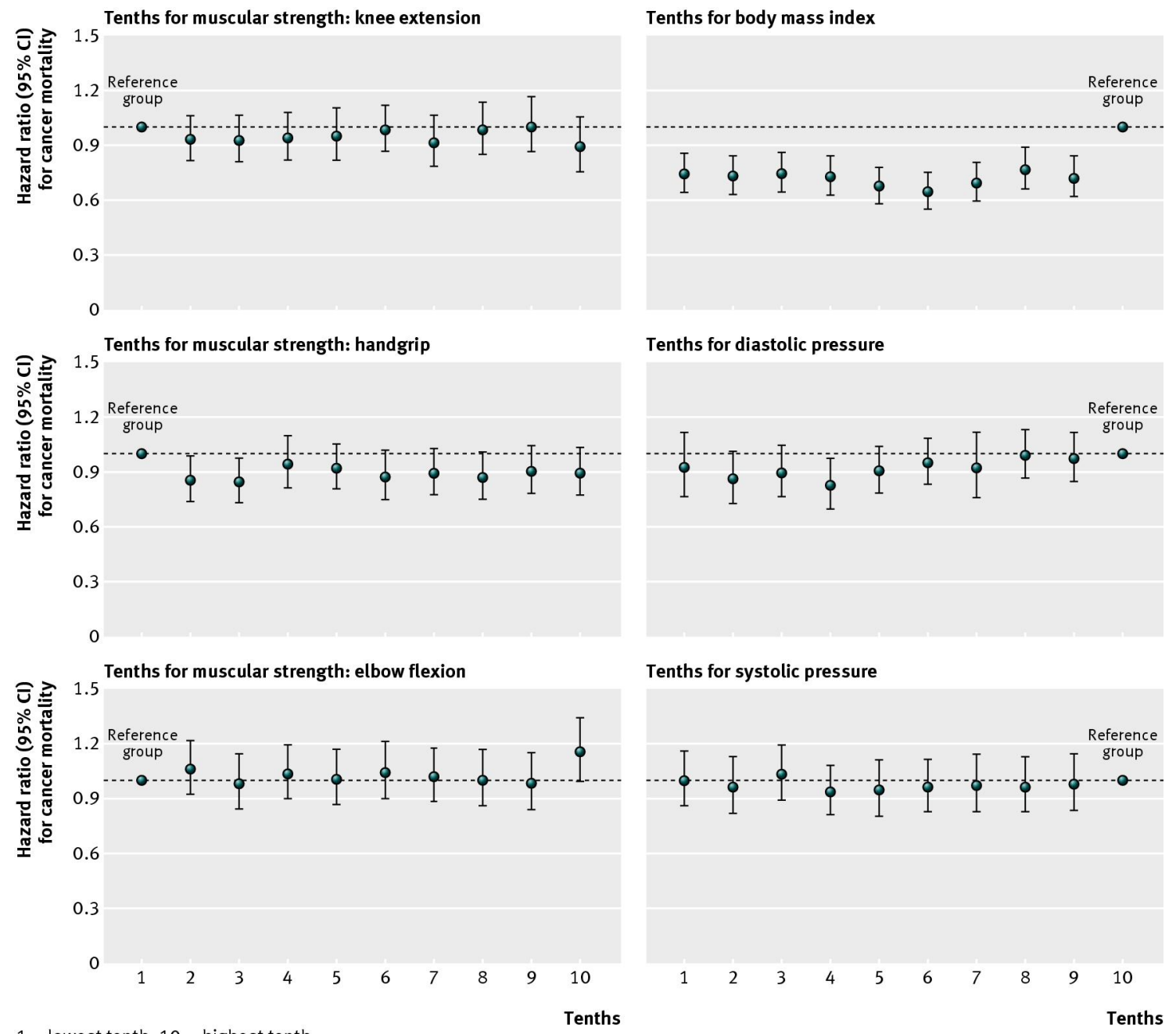

Fig 4 Hazard ratios $(95 \% \mathrm{Cl})$ for relation of muscular strength, body mass index, and blood pressure with premature death from cancer. Models were adjusted for birth cohort, conscription age, and conscription office $(n=1119790)$ 

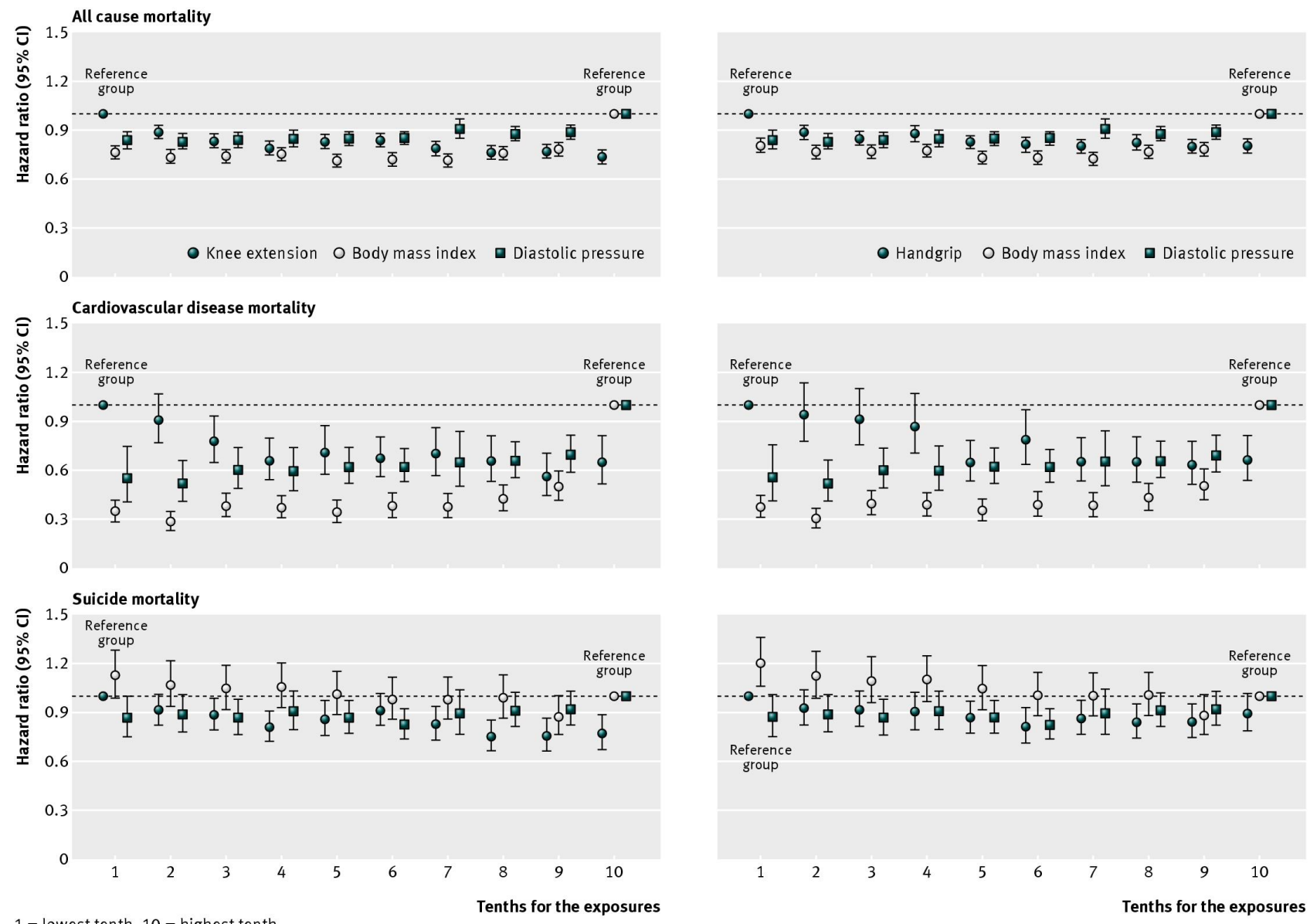

Fig 5 Hazard ratios $(95 \% \mathrm{Cl})$ for relation of muscular strength, body mass index, and blood pressure, mutually adjusted, with all cause premature death and death from cardiovascular disease and suicide. Models were additionally adjusted for birth cohort, conscription age, and conscription office 

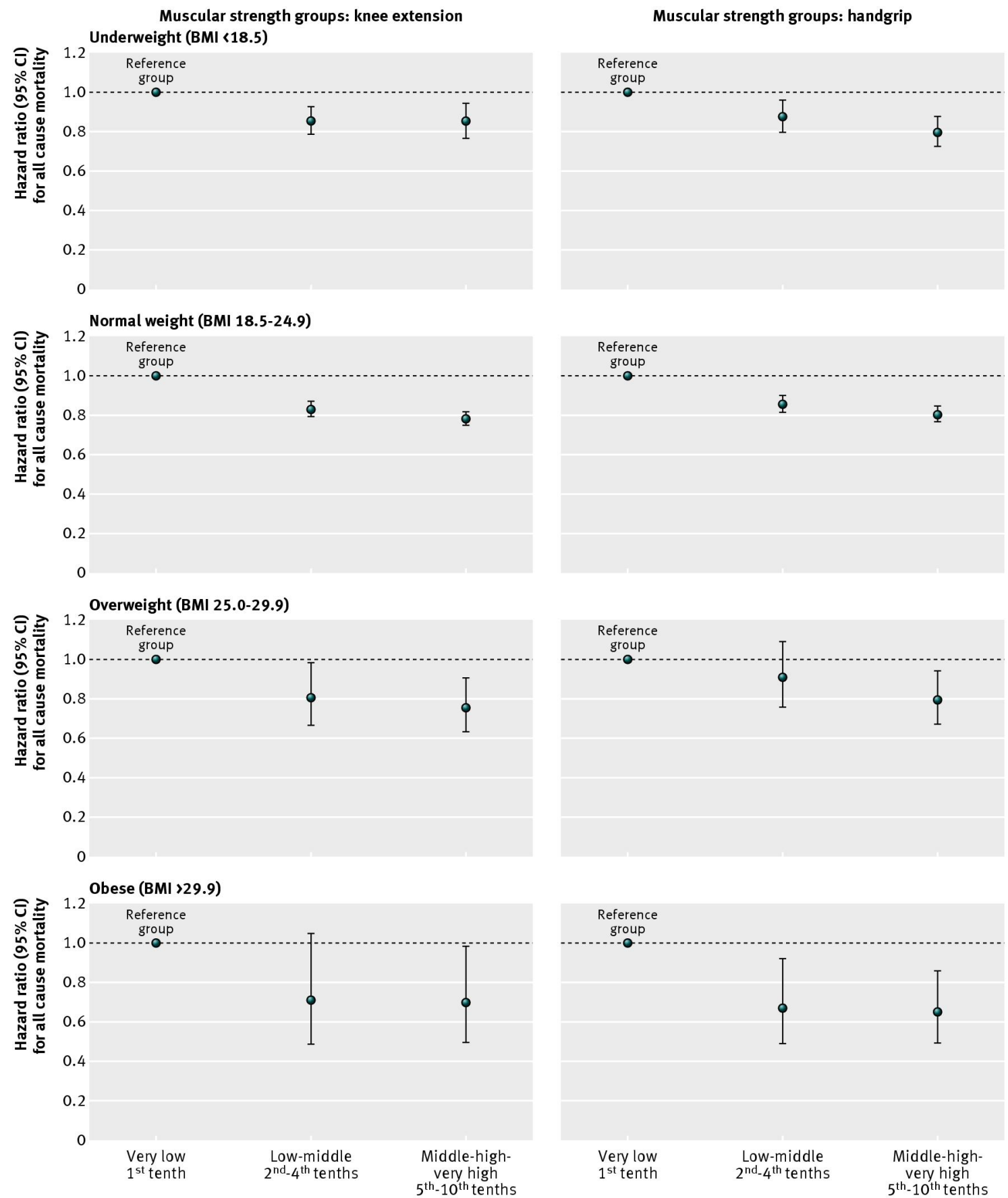

Fig 6 Hazard ratios $(95 \% \mathrm{Cl})$ for relation of muscular strength with all cause premature death, stratified by body mass index (BMI) categories. Models were adjusted for birth cohort, conscription age, and conscription office 